\title{
Opposition to Short-term Mating Predicts Anti-Atheist Prejudice
}

\author{
Jordan W. Moon ${ }^{1 *}$, Jaimie Arona Krems ${ }^{2}$, and Adam B. Cohen ${ }^{1}$ \\ ${ }^{1}$ Department of Psychology, Arizona State University, \\ 950 S. McAllister Ave., Tempe, AZ 85287, United States \\ ${ }^{2}$ The Oklahoma Center for Evolutionary Analysis (OCEAN), Department of Psychology, \\ Oklahoma State University, \\ 116 North Murray Hall, Stillwater, OK 74078, United States
}

*Author for correspondence.

Emails: jordan.w.moon@asu.edu,jaimie.krems@okstate.edu,adam.cohen@asu.edu

Note: This is the accepted version, and may differ slightly from the published version.

\section{Citation}

Moon, J. W., Krems, J. A., \& Cohen, A. B. (2020). Opposition to short-term mating predicts anti-atheist prejudice. Personality and Individual Differences, 165, Article 110136.

https://doi.org/10.1016/j.paid.2020.110136 


\begin{abstract}
Which people are most likely to harbor prejudice toward atheists? Recent research suggests that perceptions of (non)religious individuals tend to track lifestyle (i.e., family and sexual) choices. We draw on this work, proposing that anti-atheist prejudice stems, in part, from the conflict that arises among competing mating strategies. Across four studies $(N=1,855)$, we confirmed that anti-atheist prejudice is related to stereotypes about atheists' mating strategies (Pilot Study); we further found that people who favor committed mating strategies express greater levels of antiatheist prejudice, even controlling for their beliefs about cooperation (Study 1a) and religiosity (Study 1b). Finally, this effect holds even when using a semi-implicit measure of prejudice, again controlling for religiosity (Study 2). These results suggest that mating strategies provide one source of individual differences in prejudice toward atheists, consistent with the notion that this prejudice may reflect perceived differences in lifestyle rather than just abstract theological disagreements or ingroup bias.
\end{abstract}

Keywords: Atheism, prejudice, religion, mating strategies, evolutionary psychology 


\section{Opposition to Short-Term Mating Predicts Anti-Atheist Prejudice}

People view atheists negatively in a number of ways (Edgell, Gerteis, \& Hartmann, 2006;

Gervais, 2014; Harper, 2007), and these negative perceptions seem to revolve largely around distrust (Gervais, Shariff, \& Norenzayan, 2011). Anti-atheist prejudice even seems to transcend ingroup bias, as even atheists in secular nations tend to exhibit some degree of intuitive prejudice toward atheists (Gervais et al., 2017; Giddings \& Dunn, 2016).

Here, we draw on recent research on religious beliefs and mating strategies (Hone, McCauley, Pedersen, Carter, \& McCullough, 2020; McCullough, Carter, DeWall, \& Corrales, 2012; Moon, Krems, Cohen, \& Kenrick, 2019; Schmitt \& Fuller, 2015; Weeden, Cohen, \& Kenrick, 2008; Weeden \& Kurzban, 2013) to explore a novel source of individual differences in anti-atheist prejudice: competition between divergent mating strategies. Specifically, people tend to view nonreligious (vs. religious) individuals as more interested in short-term mating (i.e., more likely to engage in casual sex but less interested in long-term monogamous relationships and parenting; Moon, Krems, \& Cohen, 2018). People who oppose short-term mating tend to oppose not only promiscuous sexual behavior itself, but also tend to moralize behaviors perceived to be associated with or facilitate such sexual behavior. For example, attitudes about family and sexuality seem to drive attitudes about recreational drug use, gay marriage, abortion, religion, and a host of political attitudes (Kurzban, Dukes, \& Weeden, 2010; Petersen, 2018; Pinsof \& Haselton, 2016, 2017; Weeden et al., 2008; Weeden \& Kurzban, 2013). Thus, we propose that individuals who oppose short-term mating will exhibit greater levels of prejudice toward atheists, even controlling for the influence of religiosity.

\section{Conflict among Mating Strategies}


There is great variation in the mating tactics people adopt (Buss \& Schmitt, 1993; Gangestad \& Simpson, 2000; Heath \& Hadley, 2002). Whereas some invest significant effort in retaining a single mate and raising their offspring (a committed mating strategy), others seek out multiple simultaneous sexual relationships requiring less investment (an uncommitted mating strategy). The details of these strategies are nuanced, and in reality most people adopt "mixed" strategies that combine elements of each (Gangestad \& Simpson, 2000). For instance, even committed partners may be receptive to opportunities for short-term mating under the right circumstances.

These strategies — and the individuals that pursue them — have conflicting interests. Committed strategists invest highly in relationships, and thus stand more to lose if these relationships are easily dissolved (e.g., through infidelity or partner abandonment). Thus, a committed mating strategy is especially risky when sexual promiscuity and related behaviors are permitted or embraced. Because committed strategists invest so much in relationships, any cultural norm or policy that facilitates the dissolution of committed relationships (e.g., divorce), or that permits ad-hoc, short-term sexual relationships, shifts the cost-benefit ratio of pursuing different mating strategies, such that committed strategies are less secure. Accordingly, committed strategists tend to adopt beliefs and opinions that impose costs on sexual promiscuity and associated behavior. Such beliefs include those associated with conservative religiosity and political positions (e.g., opposition to marriage equality, birth control, reproductive freedom, and recreational drug use; Kurzban et al., 2010; Pinsof \& Haselton, 2016; Weeden et al., 2008;

Weeden \& Kurzban, 2013, 2014).

\section{Religious Beliefs and Mating Strategies}


Religious beliefs and mating strategies are tightly linked; indeed, one of the most prominent features of most world religions is that the imposition of severe costs on sexual promiscuity (Moon et al., 2019). Thus, one might expect religion to be especially appealing to individuals who benefit from such proscriptions. One of the most consistent correlates of religiosity across the world is a preference for committed mating strategies, even when controlling for other relevant variables (Haericht, 1992; Hardy \& Raffaelli, 2003; Lefkowitz, Gillen, Shearer, \& Boone, 2004; Pluhar, Frongillo, Stycos, \& Dempster-McClain, 1998; Rowatt \& Schmitt, 2003; Schmitt \& Fuller, 2015; Weeden \& Kurzban, 2013). The reproductive implications of religion seem to confer some benefits for people seeking to raise children (Reynolds \& Tanner, 1995), including increased parental certainty (Strassmann et al., 2012) and increased levels of alloparenting (Shaver, Sibley, Sosis, Galbraith, \& Bulbulia, 2019).

Further, although religious beliefs are closely linked to mating strategies, both correlational and longitudinal data are generally consistent with the notion that committed mating strategies motivate, rather than result from, religious belief (McCullough, Enders, Brion, \& Jain, 2005; Weeden, 2015; Weeden et al., 2008). In sum, one function of religion seems to be altering the incentive structure to make sexual promiscuity especially costly by imposing costs on sexual promiscuity and related behavior.

\section{Social Implications of Mating Strategies and Religion}

Recent evidence suggests that this association between people's mating strategies and religiosity may have broader social consequences. Several studies have shown that religious people are trusted more than nonreligious people (Hall, Cohen, Meyer, Varley, \& Brewer, 2015; McCullough, Swartwout, Carter, Shaver, \& Sosis, 2016; Tan \& Vogel, 2008); Moon et al. (2018) found that this effect is statistically mediated by the committed mating strategies that religious 
individuals are assumed to adopt ${ }^{1}$. When targets' religiosity and mating strategies were both specified (religious or nonreligious, committed or uncommitted), participants trusted committed (vs. uncommitted) targets, regardless of targets' reported religion. This work suggests that atheists may be viewed negatively (i.e., as untrustworthy, more opportunistic, and less cooperative), in part, because people use atheists' irreligion as a cue that they follow uncommitted mating strategies.

\section{Who Should Dislike Atheists?}

Group psychology seems to play a prominent role in understanding religion (e.g., Galen, 2012). Not surprisingly, then, religiosity is a consistent predictor of prejudice toward atheists (Edgell et al., 2006). However, even controlling for the influence of religiosity, we expected reproductive interests to explain unique variance in anti-atheist prejudice. That is, prejudice toward atheists should be most extreme among people for whom atheists not only represent an outgroup (i.e., the highly religious), but also among those who perceive atheists as following mating strategies that threaten their own.

1 Moon et al. framed these perceptions through the lens of life history theory, which many psychologists have used to describe several traits along a "fast-slow" continuum (Ellis, Figueredo, Brumbach, \& Schlomer, 2009). Recently, theorists have critiqued such a use of life history theory as inappropriate to explain such within-species trait covariation (Zietsch \& Sidari, 2019). Although perceptions of these traits seem to hang together, the studies presented here do not rely on a life history framework, but on the well-documented relation between mating strategies and religious belief. 
Given that people consistently view atheists, relative to religious individuals, as uncommitted mating strategists, we propose that mating strategies will predict unique variance in anti-atheist prejudice, with committed mating strategists exhibiting especially high levels of prejudice. We hypothesized:

(1) Individuals who oppose uncommitted mating strategies (i.e., those with a more restricted sociosexuality) will report significantly stronger anti-atheist prejudice.

(2) This association will hold when controlling for cooperative morality and religious beliefs (i.e., variables theoretically and empirically linked to anti-atheist prejudice).

(3) Participants will harbor intuitive distrust toward uncommitted strategists, much as they do toward atheists.

(4) Individuals who oppose uncommitted mating strategies will exhibit higher levels of antiatheist bias, even using a semi-implicit measure.

\section{Pilot Study}

We first conducted a pilot study to test whether stereotypes about atheists' promiscuity predict anti-atheist prejudice. That is, Moon et al. (2018) used religious vs. nonreligious targets, and did not examine trust toward atheists per se. Detailed results of the Pilot Study (as well as open data and code for all studies) are available online at https://osf.io/nhq3f/. Briefly, our results suggested that stereotypes about atheist promiscuity predict unique variance in anti-atheist prejudice (i.e., distrust and lack of warmth on a feeling thermometer), and in two of the three prejudice measures (distrust and lack of warmth), promiscuity stereotypes were a significantly stronger predictor than both general immorality stereotypes and even religiosity.

\section{Study 1a}


We first tested our prediction that committed mating strategies would predict anti-atheist prejudice using self-report measures. Past research has shown that atheists are viewed as particularly uncooperative and, thus, untrustworthy (Gervais et al., 2011). Thus, one source of individual differences in anti-atheist prejudice might be cooperative morality. People who are most susceptible to uncooperative individuals might harbor more extreme moral opposition to uncooperative behavior (Petersen, 2013; Pitesa \& Thau, 2014) and, in turn, prejudice toward groups viewed as uncooperative (Cook, Li, Newell, Cottrell, \& Neel, 2018; Schaller, Park, \& Mueller, 2003). There is some evidence that cooperative vulnerabilities predict individual differences in anti-atheist prejudice (Cook, Cottrell, \& Webster, 2015; Gervais \& Norenzayan, 2012).

We propose that committed mating strategists will report higher levels of anti-atheist prejudice, even when taking into account cooperative morality. Because one salient perception of atheists — that they are less interested in committed mating strategies — is especially threatening to committed mating strategists, we hypothesize that committed mating strategies will be associated with increased prejudice toward atheists.

\section{Method}

Participants. We recruited 233 (140 female) introductory sociology students to complete a survey for partial course credit. Participant ages ranged from 18 to 33, with a median of 19 (M $=19.44, S D=2.22$ ). We excluded 37 participants from all analyses because they failed an attention check asking participants to select "somewhat disagree" on a given item.

In Atkinson and Bourrat's (2011) analysis, the majority of correlations between belief in God and cooperative morality were between .20 and .35 . We reasoned that associations with anti-atheist prejudice may be similar. Assuming a correlation of $r=.20$, sensitivity power 
analysis using G*Power (Erdfelder, Faul, Buchner, \& Lang, 2009) indicated that we would need at least 191 participants to attain $80 \%$ power to detect this relation in a regression analysis.

Procedure. Participants responded to a series of questionnaires as part of a larger survey with unrelated measures from other researchers. Participants completed a measure of “cooperative morality," which assessed the extent to which they agreed $(1=$ never justifiable, $7=$ always justifiable) that four uncooperative behaviors are justifiable (avoiding fare on public transportation, cheating on taxes if you have a chance, paying cash for goods or services to avoid paying taxes, and driving over the speed limit; $\alpha=.72$ ). We based this measure on previously used items from the World Values Survey (Atkinson \& Bourrat, 2011; Weeden \& Kurzban, 2013). Items were reversed such that higher scores indicated view of uncooperative behavior as unjustifiable.

To assess participants' mating strategy, participants completed the 3-item attitude facet of Penke and Asendorpf's (2008) Sociosexuality Orientation Inventory-Revised (SOI; e.g., "Sex without love is okay"; $\alpha=.86$ ), which assesses sexual unrestrictedness on a 1 (strongly disagree) to 9 (strongly agree) scale. Higher SOI scores indicate an uncommitted mating strategy, while lower scores indicate a more committed strategy. They also completed the Negative Attitudes Toward Atheists scale (NATA; e.g., "Religion facilitates moral behavior in a way that nothing else can"; $\alpha=.84$ ) adapted from Gervais (Gervais, 2011), a global measure of anti-atheist prejudice.

\section{Results}

We conducted a hierarchical regression predicting NATA (see Table 1). In the first step, cooperative morality was a significant predictor of NATA. Adding SOI, $\Delta R^{2}$ was significant, $F(1,230)=70.77, p<.001$. With both variables in the model, SOI was a significant predictor of 
NATA, but cooperative morality was not. Thus, cooperative morality was a modest predictor of anti-atheist prejudice; however, when SOI was added to the model, SOI predicted unique variance in anti-atheist prejudice whereas cooperative morality did not. This suggests that committed mating strategies are significantly linked to anti-atheist prejudice.

\section{Study 1b}

Study $1 b$ tested whether mating strategy predicts anti-atheist prejudice over and above religious belief.

\section{Method}

Participants. Seven hundred ninety-one (390 female, four unspecified) introductory psychology students completed an online survey in exchange for partial course credit. Ages ranged from 18 to 49 , with a median of $19(M=19.27, S D=2.32)$. We excluded 43 participants from all analyses who failed an attention check or skipped one or more of our focal measures. Based on past research (Gervais et al., 2011; Moon et al., 2018) and Study 1a, we expected moderate effect sizes. A sensitivity power analysis suggested that we were sufficiently powered to detect small effects $\left(f^{2}=.008\right)$ in a multiple regression analysis (Erdfelder et al., 2009).

Procedure. Participants completed several measures as part of a large omnibus survey offered to all introductory psychology students. We included two religiosity items on a 1 (not at all) to 7 (very frequently) scale ("How much do you practice the requirements of your religion?" and "How often do you attend religious services?"). We combined these items with two items (“To what extent do you express or display your religious values and beliefs in public?" and "To what extent does religion play a dominant role in your life?") that were rated on a 1 (not at all) to 9 (to a great extent) scale. We standardized all four items before combining them $(\alpha=.92)$. As in 
Study 1a, participants also completed the SOI attitude facet $(\alpha=.87)$ as an index of mating strategy and the NATA scale $(\alpha=.82)$ to assess anti-atheist prejudice.

\section{Results}

We conducted a hierarchical regression predicting NATA (See Table 2). Religiosity significantly predicted NATA in the first step. Adding SOI, $\Delta R^{2}$ was significant, $F(1,788)=$ $15.47, p<.001$. In the second step, both variables explained unique variance in negative attitudes toward atheists. At the suggestion of a colleague, we tested the Religiosity $\times$ SOI interaction, which did not lead to a significant change in variance explained $(p=.174)$.

\section{Study 2}

Study 2 had two purposes. First, we sought to conceptually replicate Studies 1a and 1b using less explicit measures. In line with established research (Gervais, 2014; Gervais et al., 2011, 2017), we utilized the conjunction fallacy (Tversky \& Kahneman, 1983) to assess intuitive anti-atheist bias. In the classic conjunction fallacy, participants read a vignette about Linda, a woman who studied philosophy and holds strong opinions about social justice and discrimination. Participants are then asked which of the following is more likely: (a) Linda is a bank teller, or (b) Linda is a bank teller and a feminist. Because the profile of Linda closely mirrors that of the stereotypical feminist, participants frequently state that Linda is more likely a bank teller and a feminist, even though it is logically impossible for the conjoint probability to be higher than the probability of either one of the single probabilities (Tversky \& Kahneman, 1983). This error is unlikely, however, if the conjunction option is not representative of the description.

This method constitutes a combination of an experimental manipulation and a semiimplicit measure of the representativeness of a group with a trait or behavior (as described in the vignette). Past research has used this paradigm to explore a variety of negative intuitions about 
atheists, finding that immoral behaviors — ranging from mundane peccadillos to serial murderare intuitively associated with atheism, but not theism (Gervais, 2014; Gervais et al., 2017). When a description of an immoral actor is given, and participants are asked whether it is more likely that the targets is (a) a teacher or (b) a teacher and an atheist, people are likely to commit the conjunction fallacy, associating immorality with atheism. They are significantly less likely to commit this error, however, if the second option reads "Christian" or "believes in God" instead of "atheist."

Second, if distrust of and prejudice toward atheists stem from the perception that they are uncommitted mating strategists (Moon et al., 2018), then both atheists and uncommitted mating strategists should be viewed with similar distrust. Thus, first, we sought to test whether people harbor intuitive immoral distrust toward both atheists and unfaithful romantic partners. Although unable to test mechanisms (i.e., whether prejudice toward different targets is similar), such a finding would be consistent with the notion that mating strategies are a potent driver of distrust and prejudice.

We hypothesized that participants' own mating strategies would moderate their attitudes toward atheists, such that committed mating strategists would exhibit stronger prejudice. Following Pinsof and Haselton (2016), we operationalized mating strategy using Jackson and Kirkpatrick's (2007) short-term mating orientation scale.

We additionally hypothesized that participants would associate serial murder with unfaithful mates, to a similar (or perhaps greater) extent as they do with atheists. If distrust toward atheists largely reflects intuitions about their uncommitted mating strategies, people should display similar intuitive distrust toward unfaithful romantic partners as they do toward atheists. 


\section{Method}

Participants. An a priori power analysis using $\mathrm{G}^{*}$ Power (Erdfelder et al., 2009) based on the conjunction proportions in the US sample (64\% vs. 24\%) reported by (Gervais et al., 2017) suggested that we would need 50 participants to detect this difference in a logistic regression analysis. As we expected a similar effect size to emerge when comparing faithful vs. unfaithful romantic partners, we reasoned that we would need 50 additional participants to demonstrate this effect. To allow for additional moderation analysis (i.e., to test whether shortterm mating orientation predicts intuitive prejudice toward atheists), we exceeded this target sample size.

One hundred ninety-five introductory psychology students (104 female) completed an online survey for partial course credit. Ages ranged from 18 to 46, with a median of 19 ( $M=$ $19.48, S D=3.60)$. All analyses excluded 12 participants who never reached the relevant section of the survey and 33 participants who failed at least one of two attention check questions.

Procedure. Participants completed measures of short-term mating orientation (4-item scale, e.g., "Sex without love is okay"; $\alpha=.89$; Jackson \& Kirkpatrick, 2007) and religiosity (8item scale, e.g., "How strongly do you believe in God”, $\alpha=.97$; Cohen, Malka, Rozin, \& Cherfas, 2006). Participants then read a vignette about a man who early in life tortured animals, and later in life began killing people. Gervais and colleagues (Gervais et al., 2017) have used this vignette to demonstrate intuitive distrust of atheists. People are likely to say that the target person in this vignette is not just a teacher, but likely to be a teacher and an atheist (but not someone who believes in God).

Participants were randomly assigned to one of four conditions, varying in the conjunction target they viewed. They were asked whether it is more likely that the person in the vignette was 
a teacher, or both a teacher and one of the following four descriptors: believes in God (theist condition), does not believe in God (atheist condition), is a faithful romantic partner (faithful partner condition), is not a faithful romantic partner (unfaithful partner condition).

\section{Results}

\section{Does short-term mating orientation (negatively) predict semi-implicit prejudice}

toward atheists? First, we examined individual differences in distrust toward atheists, utilizing only the atheist $(n=45)$ and theist $(n=52)$ conditions. We ran a binary logistic regression with conjunction condition (dummy coded: $0=$ theist, $1=$ atheist), religiosity (centered), short-term mating orientation (centered), and all two-way interactions. There was a significant main effect of condition, $B=2.97, S E=0.74, Z$-value $=4.00, p<.001$, odds ratio $=19.49,95 \% \mathrm{CI}=[5.22$, 104.41] and a main effect of short-term mating orientation, $B=0.63, S E=0.30, Z$-value $=2.09$, $p=.036$, odds ratio $=1.88,95 \% \mathrm{CI}=[1.10,3.74]$. There was a significant Conjunction Condition $\times$ Religiosity interaction, $B=1.00, S E=0.49, Z$-value $=2.06, p=.049$, odds ratio $=$ $2.72,95 \% \mathrm{CI}=[1.11,7.93]$, as well as a significant Conjunction Condition $\times$ Short-Term Mating Orientation interaction, $B=-0.91, S E=0.39, Z$-value $=-2.34, p=.019$, odds ratio $=0.40,95 \%$ $\mathrm{CI}=[0.18,0.82]$. Consistent with Study $1 \mathrm{~b}$, and with past research on anti-atheist prejudice (Edgell et al., 2006; Gervais et al., 2017), anti-atheist bias was somewhat greater among participants high in religiosity (Figure 1, left panel). However, as predicted, short-term mating orientation predicted anti-atheist bias, even when accounting for the effect of religiosity, such that committed mating strategists exhibited higher levels of anti-atheist bias (Figure 1, right panel).

To summarize, religiosity significantly predicts prejudice toward atheists, consistent with past research (Gervais et al., 2017). However, even when controlling for religiosity, people low 
in short-term mating orientation are significantly more biased toward atheists, associating extreme immorality (serial murder) with atheism to a greater degree. ${ }^{2}$

\section{Do people harbor similar moral intuitions about uncommitted mates as they do}

about atheists? Next, we conducted a logistic regression, with three dummy coded variables to represent the four conditions (Figure 2). The atheist condition was coded as the base group.

Relative to the atheist condition (58\%), conjunction rates were significantly lower in the faithful partner condition $(14 \%), B=-2.35, S E=0.53, Z$-value $=-4.45, p<.001$, odds ratio $=0.10,95 \%$ $\mathrm{CI}=[0.03,0.25]$ and the theist condition $(12 \%), B=-2.13, S E=0.51, Z$-value $=-4.20, p<.001$, odds ratio $=0.12,95 \% \mathrm{CI}=[0.04,0.31]$. However, relative to the atheist condition, conjunction rates were significantly higher in the unfaithful partner condition (79\%), $B=1.02, S E=0.47, Z$ value $=2.19, p=.029$, odds ratio $=2.78,95 \% \mathrm{CI}=[1.13,7.14]$, suggesting that people harbor similar (or perhaps even more) intuitive distrust toward unfaithful romantic partners as they do toward atheists.

This analysis is unable to pinpoint the mechanism of these intuitions (e.g., whether they result from cultural evolution or some other source), or whether intuitions about atheists and unfaithful mates stem from the same source. However, past research using this method has found that people associate a variety of immoral behaviors with atheism, but not with a wide variety of religious and ethnic groups (Gervais, 2014). This finding suggests that such intuitive distrust also extends to unfaithful romantic partners. This is consistent with our reasoning that, if prejudice toward atheists stems, at least in part, from the perception that they are uncommitted mating

\footnotetext{
2 At the suggestion of a reviewer, we conducted the same analysis for faithful vs. unfaithful mates. Neither religiosity nor STMO was significantly associated with prejudice toward unfaithful mates. Full details are available at https://osf.io/nhq3f/.
} 
strategists (Moon et al., 2018), then both atheists and uncommitted mating strategists should be viewed with similar distrust.

\section{General Discussion}

Which people are most likely to harbor anti-atheist prejudice? Our data suggest that committed mating strategies are associated with higher levels of explicit anti-atheist prejudice, even when controlling for participants' cooperative moral beliefs (Study 1a) and religiosity (Studies $1 \mathrm{~b}$ and 2), and that this effect is evident whether utilizing explicit and/or semi-implicit measures of anti-atheist prejudice (Study 2).

These results imply a novel mechanism underlying anti-atheist prejudice: self-protective mating psychology. If people view atheists as uncommitted mating strategists, the same mechanisms that drive opposition to recreational drug use or gay marriage may also facilitate higher levels of prejudice toward atheists (Kurzban et al., 2010; Pinsof \& Haselton, 2016; Quintelier, Ishii, Weeden, Kurzban, \& Braeckman, 2013). Thus, anti-atheist prejudice may play a strategic role for committed strategists, protecting the viability of their own mating tactics.

\section{Contributions to Existing Literature}

The predominant explanation for anti-atheist prejudice is that religious belief spread through cultural group selection because of its positive benefits on intragroup cooperation and intergroup competition (Norenzayan et al., 2016). These beliefs included a propensity to trust coreligionists and distrust irreligious individuals.

The present results suggest a distinct but potentially complementary mechanism. Using a cultural evolutionary framework, Norenzayan et al. (2016) postulate that "Big God" religions were able to spread, not only because of intragroup cooperative norms, but also because of norms encouraging adherents to engage in high-fertility and monogamous mating strategies. 
These norms are likely associated with several reproductive benefits, including increased paternal certainty (Strassmann et al., 2012) and higher fertility rates (Frejka \& Westoff, 2008; Shaver et al., 2019). However, these benefits are at risk to the extent that other individuals break or advocate for abandoning these norms. Within a cultural evolutionary perspective, then, it makes sense that people might view atheists not only as a threat to cooperation (Cook et al., 2015; Gervais et al., 2011), but also as a mating threat.

\section{Limitations and Future Directions}

Taken together, these studies show consistent evidence that participants' own mating strategies are uniquely related to prejudice toward atheists. Still, as with many studies of individual differences, participants' mating strategies were still a measured variable (i.e., not manipulated), which limits causal inference. One way to test this relation experimentally would be to manipulate participants' sociosexuality and examine whether this leads to shifts in antiatheist prejudice. This may be possible by manipulating, for example, perceptions of sex ratio (Arnocky, Woodruff, \& Schmitt, 2016; Moss \& Maner, 2016).

Anti-atheist prejudice has been demonstrated in several cultural contexts (Gervais et al., 2017). Given the relative ubiquity of this prejudice, and data that show how religion is closely linked to mating strategies across the world (Schmitt \& Fuller, 2015; Weeden \& Kurzban, 2013), we consider it likely that anti-atheist prejudice shares similar roots across different populations. Still, the present studies rely on undergraduate participants in the United States, and crosscultural assessments of anti-atheist prejudice may reveal important differences. Although this prejudice is cross-culturally prevalent, there is notable variation, and existing explanations have done little to explain this variation. 
Perhaps one of the most fruitful implications of this framework will be examining when atheists do not face prejudice. According to our approach, prejudice toward atheists stems from the fact that religious disbelief is somewhat diagnostic of certain traits (e.g., uncommitted mating strategies and present-oriented cognition). When a person's religion is no longer diagnostic of his or her mating strategies - which may be diagnostic of his or her cooperative behavior (Jonason, Li, Webster, \& Schmitt, 2009)—perceivers should no longer use religion to infer whether or not that person will be cooperative or trustworthy. Our approach would expect that prejudice toward atheists makes little sense in societies with little variation in mating strategies or with low crime rates. In societies with little variation in these outcomes, religion may be a less reliable indicator of mating strategies or cooperativeness, and people may be less acutely attuned to such cues.

Another future direction is in examining additional nuances in perceptions of atheists, such as whether certain types of atheists face more prejudice than others. For instance, people seem to be especially willing to punish sexually available women (Muggleton, Tarran, \& Fincher, 2019); if both male and female atheists are associated with sexual promiscuity, it may be that the observed effects are stronger for female than for male atheists. However, there may be interesting reversals of these effects-people seeking short-term mating opportunities might even be motivated to find atheist partners, who might be more likely to share their uninhibited lifestyle.

Finally, future work might explore other individual differences in anti-atheist prejudice. For instance, to the extent that people in relationships are more vulnerable to the loosening of norms about mating, they may in turn show higher levels of anti-atheist prejudice. Future work 
might use cross-sectional and longitudinal data to see whether entering into (or investing highly in) committed relationships evokes higher levels of anti-atheist prejudice. ${ }^{3}$

\section{Conclusions}

Like most prejudices, anti-atheist prejudice is complex and does not stem from a single stereotype, but represents an interplay between stereotypes and the implications for perceivers. For people who are vulnerable to free riders or other cooperative threats, prejudice toward atheists might be a self-protective mechanism (Gervais \& Norenzayan, 2012); further, different religious traditions may foster higher levels of prejudice, depending on the extent to which they emphasize the morality of thoughts and behavior (Hughes, Grossmann, \& Cohen, 2015). These findings might be synthesized in an approach that considers what atheism is diagnostic of in different contexts, and the implications of these traits for social perceivers. The present results suggest that, at least in the United States, competition among mating strategies is one important component of anti-atheist prejudice. People often view atheists as sexually unrestricted and less family-oriented, which can be threatening to those who follow opposing, committed mating strategies.

3 Although two of our studies have data on relationship status (Studies $1 \mathrm{~b}$ and 2), there are not enough married participants to make meaningful estimates. In Study 1b, there did not seem to be any meaningful pattern between other relationship statuses (e.g., single vs. in a committed relationship). We suspect that questions of relationship status would be better answered in samples of older adults. 


\section{References}

Arnocky, S., Woodruff, N., \& Schmitt, D. P. (2016). Men's sociosexuality is sensitive to changes in mate availability. Personal Relationships, 23, 172-181.

Atkinson, Q. D., \& Bourrat, P. (2011). Beliefs about God, the afterlife and morality support the role of supernatural policing in human cooperation. Evolution and Human Behavior, 32, $41-49$.

Buss, D. M., \& Schmitt, D. P. (1993). Sexual strategies theory: An evolutionary perspective on human mating. Psychological Review, 100, 204-232.

Cohen, A. B., Malka, A., Rozin, P., \& Cherfas, L. (2006). Religion and unforgivable offenses. Journal of Personality, 74, 85-117.

Cook, C. L., Cottrell, C. A., \& Webster, G. D. (2015). No good without God: Antiatheist prejudice as a function of threats to morals and values. Psychology of Religion and Spirituality, 7, 217-226.

Cook, C. L., Li, Y. J., Newell, S. M., Cottrell, C. A., \& Neel, R. (2018). The world is a scary place: Individual differences in belief in a dangerous world predict specific intergroup prejudices. Group Processes and Intergroup Relations, 21, 584-596.

Edgell, P., Gerteis, J., \& Hartmann, D. (2006). Atheists as “other": Moral boundaries and cultural membership in American society. American Sociological Review, 71, 211-234.

Ellis, B. J., Figueredo, A. J., Brumbach, B. H., \& Schlomer, G. L. (2009). Fundamental dimensions of environmental risk: The impact of harsh versus unpredictable environments on the evolution and development of life history strategies. Human Nature, 20, 204-268. 
Erdfelder, E., Faul, F., Buchner, A., \& Lang, A. G. (2009). Statistical power analyses using G*Power 3.1: Tests for correlation and regression analyses. Behavior Research Methods, $41,1149-1160$.

Frejka, T., \& Westoff, C. F. (2008). Religion, religiousness and fertility in the US and in Europe. European Journal of Population, 24, 5-31.

Galen, L. W. (2012). Does religious belief promote prosociality? A critical examination. Psychological Bulletin, 138, 876-906.

Gangestad, S. W., \& Simpson, J. A. (2000). The evolution of human mating: Trade-offs and strategic pluralism. Behavioral and Brain Sciences, 23, 573-587.

Gervais, W. M. (2011). Finding the faithless: Perceived atheist prevalence reduces anti-atheist prejudice. Personality and Social Psychology Bulletin, 37, 543-556.

Gervais, W. M. (2014). Everything is permitted? People intuitively judge immorality as representative of atheists. PLoS ONE, 9, e92302.

Gervais, W. M., \& Norenzayan, A. (2012). Reminders of secular authority reduce believers' distrust of atheists. Psychological Science, 23, 483-491.

Gervais, W. M., Shariff, A. F., \& Norenzayan, A. (2011). Do you believe in atheists? Distrust is central to anti-atheist prejudice. Journal of Personality and Social Psychology, 101, 11891206.

Gervais, W. M., Xygalatas, D., McKay, R. T., van Elk, M., Buchtel, E. E., Aveyard, M., ... Bulbulia, J. A. (2017). Global evidence of extreme intuitive moral prejudice against atheists. Nature Human Behaviour, 1, Article 0151. 
Giddings, L., \& Dunn, T. J. (2016). The robustness of anti-atheist prejudice as measured by way of cognitive errors. International Journal for the Psychology of Religion, 26, 124-135.

Haericht, P. (1992). Premarital sexual permissiveness and religious orientation: A preliminary investigation. Journal for the Scientific Study of Religion, 31, 361-365.

Hall, D. L., Cohen, A. B., Meyer, K. K., Varley, A. H., \& Brewer, G. A. (2015). Costly signaling increases trust, even across religious affiliations. Psychological Science, 26, 1368-1376.

Hardy, S. A., \& Raffaelli, M. (2003). Adolescent religiosity and sexuality: An investigation of reciprocal influences. Journal of Adolescence, 26, 731-739.

Harper, M. (2007). The stereotyping of nonreligious people by religious students: Contents and subtypes. Journal for the Scientific Study of Religion, 46, 539-552.

Heath, K. M., \& Hadley, C. (2002). Dichotomous male reproductive strategies in a polygynous human society: Mating versus parental effort. Current Anthropology, 39, 369-374.

Hone, L. S. E., McCauley, T. G., Pedersen, E. J., Carter, E. C., \& McCullough, M. E. (2020). The sex premium in religiously motivated moral judgment. Journal of Personality and Social Psychology. https://doi.org/10.1037/pspp0000296

Hughes, J., Grossmann, I., \& Cohen, A. B. (2015). Tolerating the "doubting Thomas": How centrality of religious beliefs vs. practices influences prejudice against atheists. Frontiers in Psychology, 6, 1352.

Jackson, J. J., \& Kirkpatrick, L. A. (2007). The structure and measurement of human mating strategies: Toward a multidimensional model of sociosexuality. Evolution and Human Behavior, 28, 382-391. 
Jonason, P. K., Li, N. P., Webster, G. D., \& Schmitt, D. P. (2009). The dark triad: Facilitating a short-term mating strategy in men. European Journal of Personality, 23, 5-28.

Kurzban, R., Dukes, A., \& Weeden, J. (2010). Sex, drugs and moral goals: Reproductive strategies and views about recreational drugs. Proceedings of the Royal Society B: Biological Sciences, 277, 3501-3508.

Lefkowitz, E. S., Gillen, M. M., Shearer, C. L., \& Boone, T. L. (2004). Religiosity, sexual behaviors, and sexual attitudes during emerging adulthood. Journal of Sex Research, 41, $150-159$.

McCullough, M. E., Carter, E. C., DeWall, C. N., \& Corrales, C. M. (2012). Religious cognition down-regulates sexually selected, characteristically male behaviors in men, but not in women. Evolution and Human Behavior, 33, 562-568.

McCullough, M. E., Enders, C. K., Brion, S. L., \& Jain, A. R. (2005). The varieties of religious development in adulthood: A longitudinal investigation of religion and rational choice. Journal of Personality and Social Psychology, 89, 78-89.

McCullough, M. E., Swartwout, P., Carter, E. C., Shaver, J. H., \& Sosis, R. (2016). Christian religious badges instill trust in Christian and non-Christian perceivers. Psychology of Religion and Spirituality, 8, 149-163.

Moon, J. W., Krems, J. A., \& Cohen, A. B. (2018). Religious people are trusted because they are viewed as slow life-history strategists. Psychological Science, 29, 947-960.

Moon, J. W., Krems, J. A., Cohen, A. B., \& Kenrick, D. T. (2019). Is nothing sacred? Religion, sex, and reproductive strategies. Current Directions in Psychological Science, 28, 361-365. 
Moss, J. H., \& Maner, J. K. (2016). Biased sex ratios influence fundamental aspects of human mating. Personality and Social Psychology Bulletin, 42, 72-80.

Muggleton, N. K., Tarran, S. R., \& Fincher, C. L. (2019). Who punishes promiscuous women? Both women and men are prejudiced towards sexually-accessible women, but only women inflict costly punishment. Evolution and Human Behavior, 40, 259-268.

Norenzayan, A., Shariff, A. F., Willard, A. K., Slingerland, E., Gervais, W. M., McNamara, R. A., \& Henrich, J. (2016). The cultural evolution of prosocial religions. Behavioral and Brain Sciences, 39, e1.

Penke, L., \& Asendorpf, J. B. (2008). Beyond global sociosexual orientations: A more differentiated look at sociosexuality and its effects on courtship and romantic relationships. Journal of Personality and Social Psychology, 95, 1113-1135.

Petersen, M. B. (2013). Moralization as protection against exploitation: Do individuals without allies moralize more? Evolution and Human Behavior, 34, 78-85.

Petersen, M. B. (2018). Reproductive interests and dimensions of political ideology. Evolution and Human Behavior, 39, 203-211.

Phillips, N. (2017). yarrr: A companion to the e-book "YaRrr!: The pirate's guide to R." $R$ package version 0.1.6. Retrieved from www.thepiratesguidetor.com

Pinsof, D., \& Haselton, M. G. (2016). The political divide over same-sex marriage: Mating strategies in conflict? Psychological Science, 27, 435-442.

Pinsof, D., \& Haselton, M. G. (2017). The effect of the promiscuity stereotype on opposition to gay rights. PLoS ONE, 12, e0178534. 
Pitesa, M., \& Thau, S. (2014). A lack of material resources causes harsher moral judgments. Psychological Science, 25, 702-710.

Pluhar, E., Frongillo, E. A., Stycos, J. M., \& Dempster-McClain, D. (1998). Understanding the relationship between religion and the sexual attitudes and behaviors of college students. Journal of Sex Education and Therapy, 23, 288-296.

Quintelier, K. J. P., Ishii, K., Weeden, J., Kurzban, R., \& Braeckman, J. (2013). Individual differences in reproductive strategy are related to views about recreational drug use in Belgium, the Netherlands, and Japan. Human Nature, 24, 196-217.

Reynolds, V., \& Tanner, R. (1995). The social ecology of religion. New York: Oxford University Press.

Rowatt, W. C., \& Schmitt, D. P. (2003). Associations between religious orientation and varieties of sexual experience. Journal for the Scientific Study of Religion, 3, 455-465.

Schaller, M., Park, J. H., \& Mueller, A. (2003). Fear of the dark: Interactive effects of beliefs about danger and ambient darkness on ethnic stereotypes. Personality and Social Psychology Bulletin, 29, 637-649.

Schmitt, D. P., \& Fuller, R. C. (2015). On the varieties of sexual experience: Cross-cultural links between religiosity and human mating strategies. Psychology of Religion and Spirituality, 7, $314-326$.

Shaver, J. H., Sibley, C. G., Sosis, R., Galbraith, D., \& Bulbulia, J. A. (2019). Alloparenting and religious fertility: A test of the religious alloparenting hypothesis. Evolution and Human Behavior, 40, 345-324. 
Strassmann, B. I., Kurapati, N. T., Hug, B. F., Burke, E. E., Gillespie, B. W., Karafet, T. M., \& Hammer, M. F. (2012). Religion as a means to assure paternity. Proceedings of the National Academy of Sciences, 109, 9781-9785.

Tan, J. H. W., \& Vogel, C. (2008). Religion and trust: An experimental study. Journal of Economic Psychology, 29, 832-848.

Tversky, A., \& Kahneman, D. (1983). Extensional versus intuitive reasoning: The conjunction fallacy in probability judgment. Psychological Review, 90, 293-315.

Weeden, J. (2015). Losing my religion: An analysis of the decline in religious attendance from childhood to adulthood. In D. J. Slone \& J. A. Van Slyke (Eds.), The attraction of religion: A new evolutionary psychology of religion. London, UK: Bloomsbury Academic.

Weeden, J., Cohen, A. B., \& Kenrick, D. T. (2008). Religious attendance as reproductive support. Evolution and Human Behavior, 29, 327-334.

Weeden, J., \& Kurzban, R. (2013). What predicts religiosity? A multinational analysis of reproductive and cooperative morals. Evolution and Human Behavior, 34, 440-445.

Weeden, J., \& Kurzban, R. (2014). The hidden agenda of the political mind. Princeton, NJ: Princeton University Press.

Zietsch, B. P., \& Sidari, M. J. (2019). A critique of life history approaches to human trait covariation. Evolution and Human Behavior. https://doi.org/10.1016/j.evolhumbehav.2019.05.007 
Table 1: Hierarchical regression predicting negative attitudes toward atheists in Study 1a

\begin{tabular}{lrrrrr}
\hline & \multicolumn{5}{c}{ Negative Attitudes Toward Atheists } \\
\cline { 2 - 6 } Predictor & $\Delta R^{2}$ & $t$ & $\beta$ & $p$ & $95 \%$ CI \\
\hline Step 1 & $.02^{*}$ & & & & \\
$\quad$ Cooperative Morality & & 1.97 & .13 & .0497 & {$[.00, .26]$} \\
Step 2 & $.23^{* * *}$ & & & & \\
$\quad$ Cooperative Morality & & -8.41 & -.004 & .951 & {$[-.12, .11]$} \\
$\quad$ Sociosexuality & & -0.06 & -.50 & $<.001$ & {$[-0.62,-0.38]$} \\
Total $R^{2}$ & 0.24 & & & & \\
$N$ & 233 & & & & \\
${ }^{* * * *} p<.001,{ }^{*} p<.05$ & &
\end{tabular}


Table 2: Hierarchical regression predicting negative attitudes toward atheists in Study $1 \mathrm{~b}$

\begin{tabular}{|c|c|c|c|c|c|}
\hline \multirow[b]{2}{*}{ Predictor } & \multicolumn{5}{|c|}{ Negative Attitudes Toward Atheists } \\
\hline & $\Delta R^{2}$ & $t$ & $\beta$ & $p$ & $95 \% \mathrm{CI}$ \\
\hline Step 1 & $.33^{* * *}$ & & & & \\
\hline Religiosity & & 19.70 & .57 & $<.001$ & {$[.52, .63]$} \\
\hline Step 2 & $.01^{* * *}$ & & & & \\
\hline Religiosity & & 15.95 & .52 & $<.001$ & {$[.45, .58]$} \\
\hline Sociosexuality & & -3.93 & -.13 & $<.001$ & {$[-.19,-.06]$} \\
\hline Total $R^{2}$ & $.34^{* * *}$ & & & & \\
\hline$N$ & 791 & & & & \\
\hline
\end{tabular}



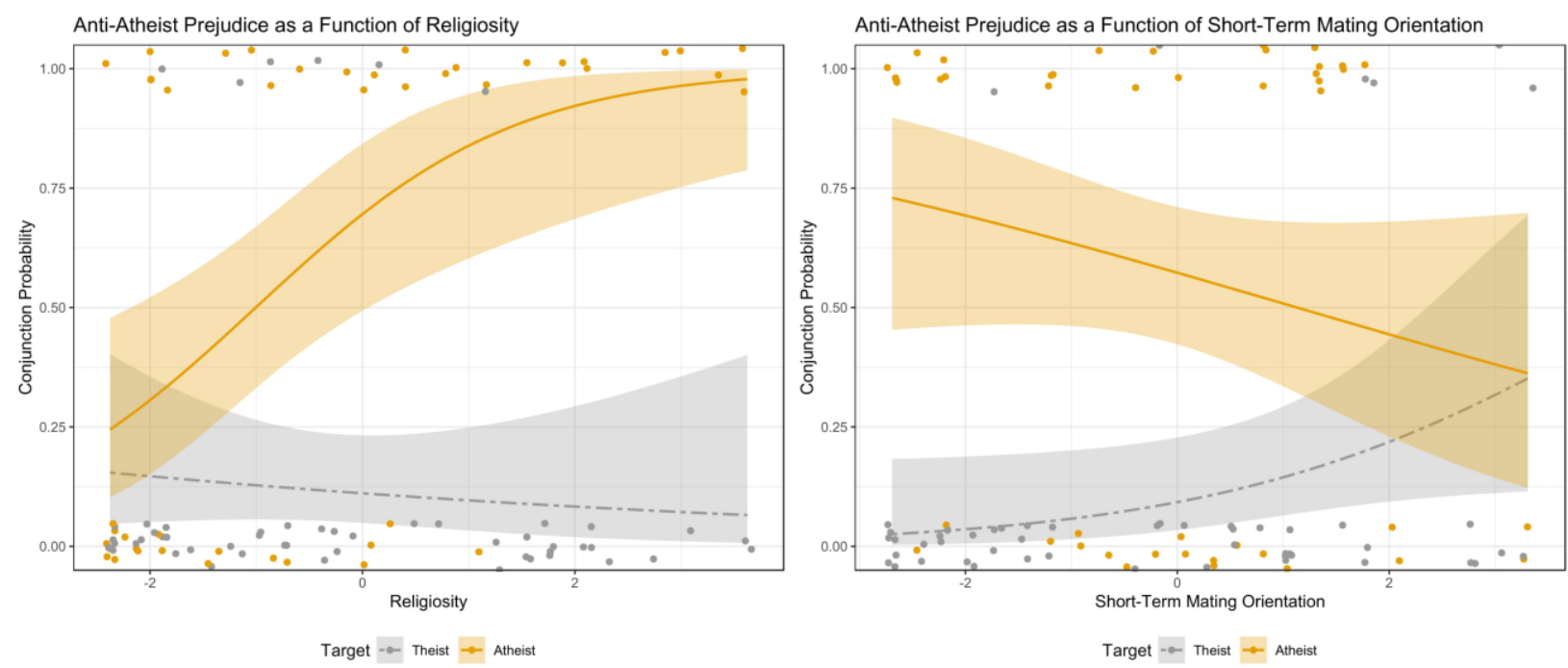

Figure 1. Conjunction rates toward atheist and theist targets in Study 2, as moderated by participant religiosity (left) and short-term mating orientation (right). Solid lines (orange area) represent conjunction rates for atheist targets while dotted lines (grey area) represent conjunction rates for theist targets. Shaded areas represent $95 \%$ confidence intervals. 


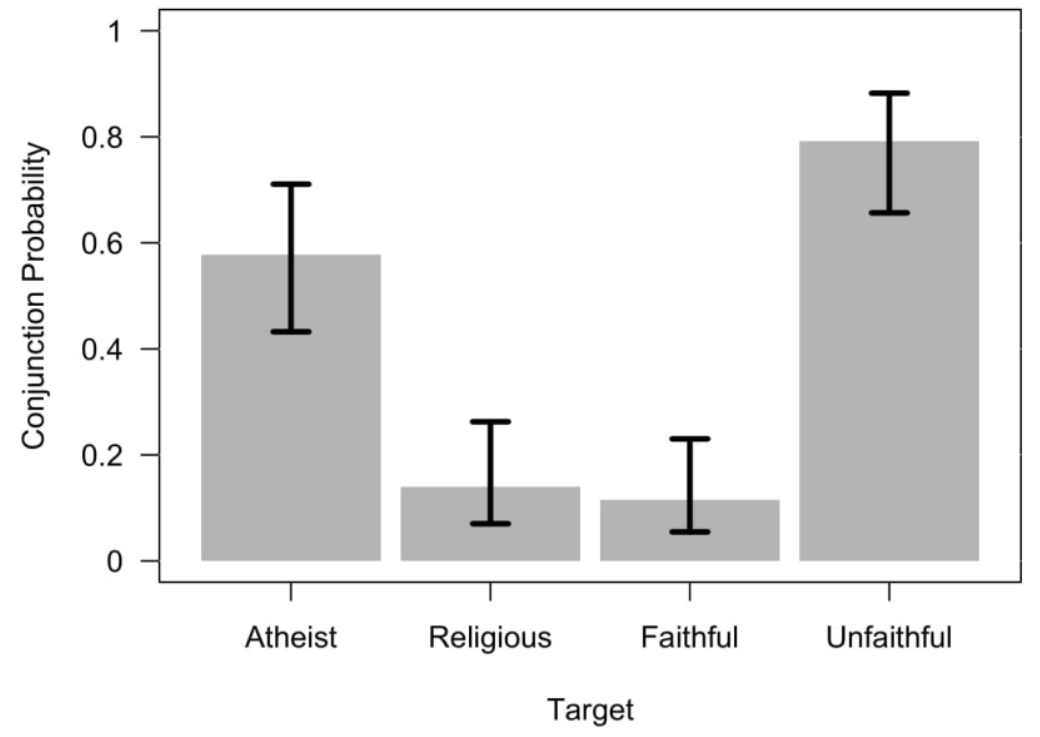

Figure 2. Conjunction error rates as a function of conjunction target in Study 2. Error bars reflect 95\% confidence intervals. Plot created using the yarrr package in R (Phillips, 2017). 